\title{
Gambaran tingkat pengetahuan mahasiswa kepaniteraan klinik Fakultas Kedokteran Universitas Tanjungpura mengenai pola asuh orang tua pada anak
}

\author{
Nadya Darapane ${ }^{1, *}$, Iit Fitrianingrum², Sari Eka Pratiwi ${ }^{2}$ \\ ${ }^{I}$ Program Studi Kedokteran, Fakultas Kedokteran, Universitas Tanjungpura, Kalimantan Barat, Indonesia \\ ${ }^{2}$ Departemen Biologi dan Patobiologi, Fakultas Kedokteran, Universitas Tanjungpura, Kalimantan Barat, Indonesia \\ *Korespondensi: darapanenadya@gmail.com
}

\begin{abstract}
Abstrak
Latar belakang: Pola asuh orang tua terhadap anak sangat mempengaruhi tumbuh kembang anak. Mahasiswa kedokteran telah dibekali dengan konsep pola asuh yang baik terhadap anak yang bertujuan untuk memberikan edukasi dan pengetahuan kepada orang tua mengenai konsep pola asuh, misalnya pola asuh gizi. Tujuan penelitian ini adalah untuk mengetahui gambaran tingkat pengetahuan mahasiswa kepaniteraan klinik Fakultas Kedokteran Universitas Tanjungpura Pontianak mengenai pola asuh. Metode: Penelitian ini merupakan penelitian deskriptif dengan desain cross-sectional. Teknik pengambilan sampel adalah total sampling dan pengambilan data dilakukan dengan menggunakan kuesioner pada 107 mahasiswa. Hasil: Distribusi proporsi responden yang paling banyak dalam penelitian ini adalah jenis kelamin perempuan $(52,3 \%)$, usia remaja akhir $(83,2 \%)$, tahun angkatan 2014 (35,5\%), lulus preklinik dengan IPK memuaskan (78,5\%), dan berasal dari Pulau Kalimantan (95,3\%). Responden dalam penelitian ini sebagian besar memiliki pengetahuan baik $(51 \%)$. Kesimpulan: Tingkat pengetahuan mahasiswa kepaniteraan klinik Fakultas Kedokteran Universitas Tanjungpura periode 2019/2020 mengenai pola asuh adalah baik.
\end{abstract}

Kata kunci: mahasiswa kepaniteraan klinik, pengetahuan, pola asuh

\section{Description of knowledge level of clinical students at Faculty of Medicine Tanjungpura University about parenting style}

\begin{abstract}
Background: Parenting style will affect a child's growth and development. Medical students have learned about parenting style to be able to educate parents about the concept of parenting style, such as food parenting. The purpose of this study was to describe the knowledge level of clinical students at Faculty of Medicine Tanjungpura University about parenting style. Methods: This research was a descriptive study using cross-sectional design. Sample was obtained by total sampling technique and 107 respondents were asked to fill a questionnaire. Results: The distribution of most respondents in this study were female $(52.3 \%)$, late adolescence $(83.2 \%)$, students of medicine 2014 (35.5\%), satisfactory GPA (78.5\%), and comes from Kalimantan (95.3\%). The test results showed the respondents in this study had a good level of knowledge (51\%). Conclusions: The clinical students at Faculty of Medicine Tanjungpura University have a good level of knowledge.
\end{abstract}

Keywords: clinical medical students, knowledge level, parenting style

\section{Pendahuluan}

Masalah gizi anak perlu ditanggulangi karena memiliki akibat buruk yang begitu luas dalam berbagai aspek kehidupan anak, mulai dari segi ekonomi, pendidikan, dan kapasitas yang berpengaruh terhadap tumbuh kembang dan masa depan anak. ${ }^{1}$ Beberapa penelitian menunjukkan bahwa anak dengan kondisi gizi buruk dapat beresiko memiliki prestasi yang buruk di sekolah yang 
beresiko menjadi orang dewasa dengan pendidikan yang kurang memadai, ekonomi rendah, kesehatan rendah dan cenderung mudah terserang penyakit. ${ }^{1}$

Data Riset Kesehatan Dasar (Riskesdas) tahun 2018, memperlihatkan bahwa Indonesia memiliki angka status gizi buruk pada balita usia 0-23 bulan sebesar 3,8\%, sedangkan angka untuk status gizi kurang adalah $11,4 \%$. Hal tersebut cukup sesuai dengan data hasil Pemantauan Status Gizi (PSG) oleh Kementerian Kesehatan tahun 2017, yaitu angka status gizi buruk sebesar 3,5\% pada balita usia 0-23 bulan dan angka status gizi kurang sebesar 11,3\%. Pada tahun 2018, Nusa Tenggara Timur menjadi Provinsi dengan angka tertinggi gizi buruk dan gizi kurang pada balita usia 0-23 bulan, dan pada tahun yang sama Jawa Barat menjadi provinsi dengan persentase terendah atau dengan kata lain memiliki angka status gizi baik yang tertinggi. ${ }^{2}$

Gizi makanan yang kurang memadai dan adanya keadaan atau penyakit tertentu pada anak dapat menjadi satu dari sekian banyak faktor yang menghambat tumbuh kembang anak sehingga menyebabkan gizi buruk pada anak. Keadaan tersebut dapat terjadi karena pola asuh ibu yang buruk. ${ }^{2}$ Sikap atau praktik orang tua dalam mengasuh anak balita perlu ditinjau karena merupakan aspek yang berguna untuk menyusun dan mengupayakan perbaikan apabila disadari bahwa pola asuh yang diterapkan tersebut kurang baik.

Mahasiswa Kedokteran telah dibekali dengan konsep pola asuh yang baik terhadap anak yang bertujuan untuk memberikan edukasi dan pengetahuan kepada orangtua mengenai konsep pola asuh, misalnya pola asuh gizi. Hal tersebut didukung dengan modul dan stase wajib yang harus diikuti oleh mahasiswa kedokteran, yaitu modul tumbuh kembang anak bagi mahasiswa preklinik serta stase komunitas dan anak bagi mahasiswa kepaniteraan klinik. Promosi kesehatan termasuk ke dalam SKDI (Standar Kompetensi Dokter Indonesia) di area pengelolaan masalah kesehatan, dimana tertulis bahwa lulusan kedokteran berkompetensi melaksanakan edukasi dan promosi kesehatan pada individu, keluarga dan masyarakat. Salah satu contohnya adalah edukasi mengenai pola asuh orangtua terhadap anak. ${ }^{3}$

Sejauh ini penelitian mengenai tingkat pengetahuan mahasiswa kepaniteraan klinik Fakultas Kedokteran tentang pola asuh belum pernah dilakukan. Selain itu, pengetahuan yang baik akan pola asuh bagi mahasiswa kepaniteraan klinik sangat diperlukan dalam memberikan edukasi pola asuh kepada orangtua. Oleh karena itu, Peneliti tertarik untuk mengetahui tingkat pengetahuan tentang pola asuh pada mahasiswa kepaniteraan klinik di Fakultas Kedokteran Universitas Tanjungpura Pontianak.

\section{Metode}

Penelitian ini bersifat deskriptif. Penelitian dilakukan pada bulan Agustus 2020 secara daring melalui forum group chat dan personal chat. Pengumpulan data dilakukan dengan cara memberikan kuesioner yang telah diuji validitas dan reliabilitasnya pada sampel penelitian untuk menilai tingkat pengetahuan mengenai pola asuh pada subjek penelitian yaitu mahasiswa kepaniteraan klinik Fakultas Kedokteran dengan menggunakan aplikasi google form. Subjek penelitian ini adalah responden yang memenuhi kriteria inklusi, dengan jumlah 107 orang. Jawaban dari kuesioner akan dikaji dan ditelaah. Proses pengkajian data tersebut akan dilakukan dengan bantuan sistem komputer melalui tahap editing, coding, data entry atau processing,dan pembersihan data (cleaning). Editing adalah upaya pemeriksaan dan pengoreksian kembali isi kuesioner. Coding merupakan kegiatan mengganti data dalam bentuk kalimat atau huruf menjadi data numerik. Data yang telah dilakukan coding akan diinput ke dalam program komputer. Setelah semua data dimasukkan, dilakukan pemeriksaan ulang untuk mengetahui adanya kemungkinan kesalahan kode, kekurangan dan ketidaklengkapan yang selanjutnya akan dilakukan pembetulan (data cleaning).

\section{Hasil}

Penelitian dilakukan secara online melalui google form. Subjek penelitian ini adalah mahasiswa kepaniteraan klinik yang memenuhi kriteria inklusi dan eksklusi, dengan jumlah sampel sebanyak 123 mahasiswa kepaniteraan klinik Fakultas Kedokteran Universitas Tanjungpura periode 2018/2020, dengan keterangan didapatkan sampel sebanyak 107 responden yang memenuhi kriteria inklusi dan eksklusi, 10 orang tidak dapat dihubungi dan 6 orang lain yang tidak bersedia untuk menjadi responden. Adapun karakteristik dari 107 responden tersebut ditampilkan pada tabel 1 . 
Tabel 1 Karakteristik umum responden penelitian

\begin{tabular}{ccc}
\hline $\begin{array}{c}\text { Karakteristik } \\
\text { responden }\end{array}$ & $\begin{array}{c}\text { Frekuensi } \\
\text { (orang) } \\
\mathrm{n}=107\end{array}$ & Persentase \\
\hline Jenis Kelamin & 51 & 47,7 \\
Laki-laki & 56 & 52,3 \\
Perempuan & & \\
Usia & 89 & 83,2 \\
Remaja akhir & 18 & 16,8 \\
Dewasa awal & & \\
Angkatan & 3 & 2,8 \\
2009 & 4 & 3,7 \\
2010 & 1 & 0,9 \\
2011 & 8 & 7,5 \\
2012 & 20 & 18,7 \\
2013 & 38 & 35,5 \\
2014 & 33 & 30,8 \\
2015 & & \\
IPK Preklinik & 5 & 4,7 \\
2,00-2,75 & 81 & 78,5 \\
2,76-3,50 & 21 & 16,8 \\
3,51-4,00 & & \\
Asal Daerah & 102 & 95,3 \\
Kalimantan & 5 & 4.7 \\
Luar Kalimantan & & \\
\hline Sumbr: Data primer, 2020 & &
\end{tabular}

Sumber: Data primer, 2020

Penelitian yang telah dilakukan menunjukkan hasil bahwa sebagian besar mahasiswa kepaniteraan klinik Fakultas Kedokteran Untan memiliki tingkat pengetahuan baik mengenai pola asuh, yaitu sebanyak 51\% mahasiswa dari jumlah keseluruhan. Sementara itu mahasiswa yang memiliki tingkat pengetahuan cukup sebanyak $48 \%$ dan kurang sebanyak 1\% (Gambar 1). Hal ini sejalan dengan penelitian Prita Rahayu ${ }^{4}$ yang menyatakan bahwa mayoritas mahasiswa FKUI memiliki tingkat pengetahuan yang baik mengenai gizi kurang.

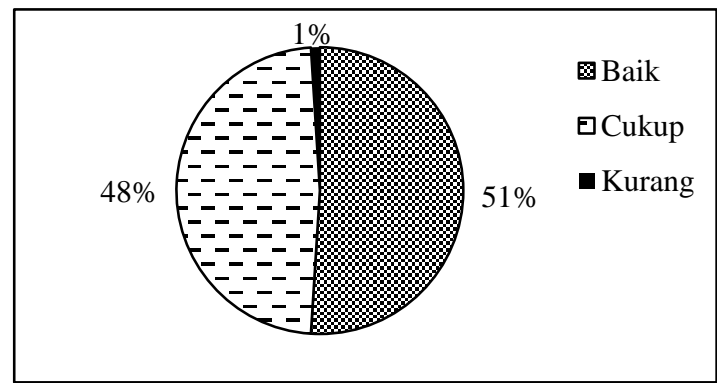

Gambar 1 Distribusi responden berdasarkan tingkat pengetahuan

Distribusi pengetahuan berdasarkan jenis kelamin dapat dilihat pada tabel 2. Dari 51 mahasiswa kepaniteraan klinik yang berjenis kelamin laki-laki dan 56 mahasiswi kepaniteraan klinik yang berjenis kelamin perempuan, didapatkan bahwa mahasiswa kepaniteraan klinik berjenis kelamin laki-laki sebagian besar memiliki tingkat pengetahuan baik dan cukup, dengan persentase masing-masing adalah pengetahuan baik $49 \%$ dan pengetahuan cukup juga sebesar $49 \%$. Mahasiswa kepaniteraan klinik berjenis kelamin perempuan, didominasi oleh mahasiswa dengan tingkat pengetahuan baik yaitu sebesar $53,6 \%$.

Tabel 2. Pengetahuan berdasarkan jenis kelamin

\begin{tabular}{lcc}
\hline \multirow{2}{*}{ Pengetahuan } & \multicolumn{2}{c}{ Jenis kelamin } \\
\cline { 2 - 3 } & Laki-laki & Perempuan \\
\hline Baik & $25(49 \%)$ & $30(53,6 \%)$ \\
Cukup & $25(49 \%)$ & $26(46,4 \%)$ \\
Kurang & $1(2 \%)$ & $0(0 \%)$ \\
Total & $51(100 \%)$ & $56(100 \%)$ \\
\hline Sumber: Data primer, 2020 &
\end{tabular}

Distribusi pengetahuan yang didasarkan pada perbedaan usia dapat dilihat pada tabel 4.3 , dari 89 mahasiswa kepaniteraan klinik yang berusia remaja akhir (17-25 tahun) dan 18 mahasiswa kepaniteraan klinik yang berusia dewasa awal (26-35 tahun), dapat diketahui bahwa responden kelompok remaja akhir (usia 17-25 tahun) rata-rata mempunyai tingkat pengetahuan baik (53\%) dan responden kelompok dewasa awal (usia 26-35 tahun) rata-rata memiliki tingkat pengetahuan yang cukup (56\%).

Tabel 3. Pengetahuan berdasarkan usia

\begin{tabular}{lcc}
\hline \multirow{2}{*}{ Pengetahuan } & \multicolumn{2}{c}{ Usia } \\
\cline { 2 - 3 } & Remaja akhir & Dewasa awal \\
\hline Baik & $47(53 \%)$ & $8(44 \%)$ \\
Cukup & $41(46 \%)$ & $10(56 \%)$ \\
Kurang & $1(1 \%)$ & $0(0 \%)$ \\
Total & $89(100 \%)$ & $18(100 \%)$ \\
\hline Sur
\end{tabular}

Sumber: Data primer, 2020

Distribusi pengetahuan berdasarkan IPK dapat dilihat pada tabel 4.4. Hasil pada tabel menunjukkan bahwa responden dengan rentang IPK 2,00-2,75 sebagian besar memiliki tingkat pengetahuan cukup (60\%), responden dengan rentang IPK 2,76-3,50 sebagian besar memiliki tingkat pengetahuan cukup (51\%), dan responden dengan rentang IPK 3,51-4,00 sebagian besar memiliki tingkat pengetahuan baik $(67 \%)$.

Tabel 4. Pengetahuan berdasarkan IPK

\begin{tabular}{lccc}
\hline \multirow{2}{*}{ Pengetahuan } & \multicolumn{3}{c}{ IPK } \\
\cline { 2 - 4 } & $2,00-2,75$ & $2,76-3,50$ & $3,51-4,00$ \\
\hline Baik & $2(40 \%)$ & $39(48 \%)$ & $14(67 \%)$ \\
Cukup & $3(60 \%)$ & $41(51 \%)$ & $7(33 \%)$ \\
Kurang & $0(0 \%)$ & $1(1 \%)$ & $0(0 \%)$ \\
Total & $5(100 \%)$ & $81(100 \%)$ & $21(100 \%)$ \\
\hline Sumber: Data primer, 2020 & &
\end{tabular}




\section{Pembahasan}

Tabel 2 menunjukkan bahwa persentase terbesar tingkat pengetahuan baik adalah subjek penelitian berjenis kelamin perempuan dengan jumlah 30 mahasiswa $(53,6 \%)$. Hal ini dikarenakan seseorang dengan jenis kelamin perempuan memiliki moral yang lebih tinggi dibanding dengan laki-laki, termasuk dalam hal pengetahuan pola asuh pada anak. Hal ini sesuai dengan penelitian Karina, Hastuti, dan Alfiasari ${ }^{5}$, dimana dinyatakan bahwa karakter anak laki-laki dan anak perempuan berbeda. Hasil penelitian menunjukkan adanya rentang yang nyata antara tingkat pengetahuan moral pada individu laki-laki dan individu perempuan. Sebagian besar, pengetahuan, perasaan dan tindakan yang berhubungan dengan nilai moral pada sifat anak perempuan lebih tinggi dibandingkan dengan anak laki-laki. ${ }^{6}$ Namun, baik laki-laki maupun perempuan diharapkan memiliki pengetahuan yang baik akan pola asuh, sebab keduanya harus mampu mengedukasikan masyarakat mengenai pola asuh yang baik, dan pada praktiknya juga baik seorang laki-laki maupun perempuan harus bisa mengimplementasikan pola asuh yang baik kepada anaknya. $^{7}$

Responden kelompok remaja akhir sebagian besar memiliki tingkat pengetahuan baik (53\%) dan responden kelompok dewasa awal sebagian besar memiliki tingkat pengetahuan cukup (56\%). Hal ini dapat dilihat pada tabel 4.3. Dalam penelitian ini diharapkan semakin tinggi atau semakin dewasa usia seseorang, maka semakin tinggi pula tingkat pengetahuan yang dimilikinya. Namun kedewasaan seseorang tidak semata-mata hanya dapat diukur berdasarkan usia, sehingga data hasil penelitian ini kurang sesuai dengan teori yang ada, dimana usia mempengaruhi daya pemahaman dan pola pikir suatu individu. Setiap rentang usia memiliki daya dan kapasitas yang tidak sama dalam mempelajari suatu hal, yang menyebabkan adanya perbedaan pada tingkat pengetahuan. ${ }^{8,9,10}$

Responden dengan tingkat pengetahuan baik sebagian besar adalah mahasiswa dengan rentang IPK cum laude $(3,51-4,00)$ dengan persentase $67 \%$. Sementara itu mahasiswa dengan IPK memuaskan dan cukup memuaskan memiliki tingkat pengetahuan yang cukup. Hal ini dapat dilihat apda tabel 4.4. IPK atau Indeks prestasi mahasiswa merupakan salah satu tolok ukur prestasi atau kemampuan mahasiswa, sehingga bisa diperkirakan seharusnya semakin tinggi IPK seseorang membuktikan semakin tinggi tingkat pengetahuan seseorang. ${ }^{11}$

Pengetahuan merupakan hasil dari mengetahui suatu hal, dan mengetahui merupakan hasil dari seseorang melakukan pengindraan terhadap suatu objek tertentu. Mahasiswa kepaniteraan klinik yang memiliki tingkat pengetahuan baik dikarenakan mahasiswa sudah mempelajari materi mengenai pola asuh pada masa pendidikan preklinik yaitu saat mempelajari modul tumbuh kembang anak dan ada juga beberapa mahasiswa yang sudah mempelajarinya pada masa kepaniteraan klinik yaitu pada stase anak dan stase komunitas. ${ }^{11}$

Rentang atau skor pengetahuan untuk penyajian secara deskriptif dikategorikan berdasarkan skala Guttman, yaitu pengetahuan baik memiliki skor $76 \%-100 \%$, pengetahuan cukup memiliki skor $56 \%-75 \%$, dan pengetahuan kurang memiliki skor $<56 \% .^{12}$

\section{Kesimpulan}

Berdasarkan hasil dan pembahasan penelitian yang dilakukan maka dapat disimpulkan bahwa tingkat pengetahuan mahasiswa kepaniteraan klinik Fakultas Kedokteran Universitas Tanjungpura periode 2019/2020 mengenai pola asuh adalah baik.

\section{Konflik Kepentingan}

Tidak terdapat konflik kepentingan dalam penelitian ini.

\section{Daftar Pustaka}

1. Kemenkes. Hasil pemantauan status gizi (PSG) dan penjelasannya. Jakarta: Kementerian kesehatan RI; 2017. p.4-10.

2. Kementerian Kesehatan RI. Profil kesehatan indonesia tahun 2018. Jakarta: Kementerian Kesehatan RI; 2019. p.153.

3. Konsil Kedokteran Indonesia. Standar kompetensi dokter indonesia. Jakarta: KKI; 2012. p.6.

4. Rahayu P. Pengetahuan, sikap dan perilaku mahasiswa FKUI tentang gizi kurang pada tahun 2011 serta faktor-faktor yang berhubungan [skripsi]. Jakarta: FKUI; 2012.

5. Karina K, Hastuti D, Alfiasari A. Perilaku bullying dan karakter remaja serta kaitannya dengan karakteristik keluarga dan peer group. J Ilmu Keluarga \& Konsumen. 2013; 6(1):20-9.

6. Siregar IH. Pengetahuan mahasiswa kepaniteraan klinik tentang kesalahan dan kegagalan pembuatan 
radiografi intraoral pada Fakultas Kedokteraan Gigi di salah satu universitas di Jawa Barat [skripsi]. Medan: Universitas Sumatera Utara; 2013.

7. Suranadi IW. Tingkat pengetahuan tentang bantuan hidup dasar (BHD) mahasiswa Fakultas Kedokteran Universitas Udayana [skripsi]. Denpasar : Universitas Udayana; 2017.

8. Julianto V. Meningkatkan memori jangka pendek dengan karawitan. Indigenous: Jurnal Ilmiah Psikologi. 2017;2(2):137-47.

9. Irman MF. Analisis pengaruh jenis kelamin, IPK, dan pengalaman kerja terhadap tingkat financial literacy. Journal of Economic, Business and Accounting. 2018

\section{2(1):41-56.}

10. Kurniati A. Kontribusi pola asuh orang tua dalam pendidikan karakter anak (studi kasus di Dusun Tempurau Desa Batu Buil Kecamatan Belimbing). J Pendidikan Dasar Perkhasa. 2016;2(2):212-20.

11. Loren, Jeff. Gambaran pengetahuan mahasiswa Fakultas Kedokteran Universitas Sumatra Utara terhadap rokok [skripsi]. Medan: Universitas Sumatra Utara; 2010.

12. Masturoh I, Anggita NT. Metodologi penelitian kesehatan. Jakarta : Kementerian Kesehatan Republik Indonesia; 2018. p.57. 